\title{
DESIGNING WITH NATURE LATERAL THINKINGE AS A DESIGN STRATEGY FOR FOUNDATION YEAR STUDIO IN BACHELOR OF ARCHITECTURE
}

\author{
M uhammad Waqas* \\ Uzma Kabir** \\ Dr. Shahida M ansoor***
}

\begin{abstract}
The role of educationists is to help students develop quality thinking through self-reflection and discovering. Nature is on top of the index of discovery. This study contains measures for enhancing sensitivity towards nature, with the basic assumption that nature is the primary guide that generates diverse empirical and creative design processes in architecture education. Understanding the importance of nature and environment at beginner level is more effective, as working with nature will become intrinsic part of students' design thinking. Foundation studio at the Department of Architecture at COMSATS University, Islamabad, serves as junction of art, architecture and nature, which works towards developing the critical thinking process.
\end{abstract}

In order to bring students closer to the goal of inclusion of nature in the core design thinking "Impulsive" teaching methodology was adopted. Lateral thinking, one of the tools of impulsive system of teaching, was carried through in three stages: observation of nature, recording observations in variety of media and correlating observed natural phenomena to solve a given design problem. In this case the design problem was a piece of furniture, using a very thin sheet of steel that had a thickness of sixteen to twenty gauge.

The study highlights a studio model by describing one of the experimental processes that was designed to augment originality in architectural design thinking. A specific natural phenomenon that is wind, was focused upon as a natural parameter of this study. The objective of the studio model was to offer students an organic tool for exploring new design possibilities. This helped students to visit and revisit the central idea for multiple interpretations, in order to relate it with architectural design process at any stage of design development.

Keywords: Architecture Education, Design Process, Natural Phenomena, Wind, Impulsive System

\section{INTRODUCTION}

In the modern globalized world, the role of an educationist is to help students in quality thinking through self-reflection and self-education. Sensitivity towards nature however should be taught as a fundamental of diverse empirical and creative design process, that is followed in architectural education. Understanding the importance of nature and the environment at earlier stages could prove to be more effective, as working with nature could become an intrinsic part of students' design thinking.

The study began with various approaches to creative learning and led to some practical implications. Students were asked to explore ephemeral qualities of nature, as they were exposed to a variety of methods and creative design processes. In order to bring students closer to the goal of inclusion of nature in structural presence of architecture, an experimental teaching methodology was adopted. Students gained confidence to comprehend and represent nature in unfamiliar, abstract and subjective manners. As their decision making in representing nature improved, so did the ability to extend imagination and innovation. During the process of making, the role of perception, materiality and unknown was addressed, by respecting instinctive response to the natural beauty of materials and making it part of the preconceived ideas.

\footnotetext{
* Muhammad Waqas, Architect, Educationist- Assistant Professor, Department of Architecture, COMSATS University Islamabad..

Email Correspondance: vacas@comsats.edu.pk

** Uzma Kabir: Architect, Educationist- Assistant Professor, Department of Architecture, COMSATS University Islamabad.

Email Correspondance: uzmakabir@comsats.edu.pk

*** Dr. Shahida Mansoor: Artist, Educationist- Associate Professor, Department of Architecture, COMSATS University Islamabad.

Email Correspondance: shahida.masoor@comsats.edu.
} 
This paper elucidates on an experimental process that was designed to augment flexibility in architectural design thinking. The study proposes that this experimental design process can inculcate in students the aptitude to observe nature, which is ever changing, and can also prepare students to visit and revisit central ideas in new ways, in an architectural design process at any stage of design development.

The research objective was to recommend a trans-disciplinary design method in foundation studio, that brought students closer to the goal of transforming everyday experiences of surrounding into a meaningful design activity, by immersing them in the observation of and interaction with nature.

\section{Research}

This study was planned in an empirical manner. Relevant instruction concepts were analyzed to form a roadmap and referential ground for practical implications. Impulsive teaching methodology was adopted for the purpose. Lateral thinking, one of the tools of impulsive system of teaching was carried out in three stages; observation of nature, recording observations in variety of mediums and correlating observed natural phenomena to solve a given design problem, i.e. a practical piece of furniture to be designed and justified by its use.

The studio was designed with multidisciplinary ethos. The content, studio method and instruction model was designed by a group of instructors belonging to multiple disciplines. The studio team comprised of a sculptor, painter and an architect. The design of a piece of furniture as the end product was considered to be more convincing in terms of practicality and aesthetics as it covered both the dimensions i.e. functional and formal. The projects that are presented as examples in this paper were graded highest by a multidisciplinary jury panel.

\section{Literature Review}

Nature has played a vital role in the development of man's psychological and physical landscape. Human beings have always appropriated forms, processes and mechanisms from nature. There is a very clear primordial link between human race's meteoric cognitive development and adaptation to harsh habitats through observation/learning from nature. Nature has awed and inspired man's creative endeavors since time immemorial. The evidence is splashed across different-cultures and crafts across the globe (Fletcher, 2001; Kellert, 1997).
However, the relationship of architectural practice with nature is replete with inherent dichotomies and contradictions. On one hand nature has been and will be a treasure trove of ideas and synthesis of knowledge for architects, on the other hand whenever man builds, the basic intent is to push nature away to pave way for a safe and progressive life.

Architectural theory has however long taken cues from nature. The concepts of growth and integration have come directly from nature. The observation and interaction with nature has played a vital role in shaping aesthetic preferences for what is termed as beautiful or ugly, safe or dangerous (Fletcher, 2001; Bayley, 2012). Man's urge to depict the beautiful, benign nature and worship horrific, cruel nature has led to innumerable artistic expressions on cave walls as paintings/drawings, as totem poles and as ziggurats or pyramids. With particular reference to architecture, builders have always taken their cues from nature, either as direct inspiration or as translation of natural processes into their buildings and structures.

Apart from being a source of inspiration, a teacher and a therapist, nature in all its beauty and ugliness is an intrinsic part of the environment and life as we know it. However, the anthropocentricity of man has led to a world view held by many today, that nature is some kind of an inexhaustible resource bank in service of mankind. The scientific research over the last five decades has proven that unless consumed with responsibility and a sense of stewardship, this resource bank is not renewable (Stern 2006; Raouf, Fuentes and Thomas 2007; Wines, 2008).

Consequently, the architectural community has appropriated myriad of design ideologies and etymologies from across different domains to practice sustainability in use of materials and resources. Where on one hand consumerism, pursuit of temporality has dug its claws into the profession, at the same time a parallel sustainable sensibility has always been practiced side by side. The problem is that despite architectural practitioner's considerable efforts, the construction industry remains the major plunderer and polluter of world resources (Global Status Report, 2017). Designers build spaces devoid of pleasure and fascination through technological and virtual means for humans that are in total disconnect from ecology of the natural world (Wines, 2008).

To bring about a change in the thinking processes of architects, a change is needed in the architectural curricula and in mindsets. Pedagogues and andragogues cannot shirk away from the dire need to connect the students to their 
surrounding environment on a subliminally intrinsic level. Understanding the importance and appreciation of nature and environment at earlier stages can prove to be more effective, in the sense that working with nature can become intrinsic part of students' design thinking.

Bailey (1904), an eminent scholar on nature study, described the study of nature as a process that encourages observation of nature and consequently drawing of sound conclusions. He goes on to explain the advantage of nature study as an endeavor that frees the imagination from systematic order and relational sequences of objects. As a result, one learns by developing sympathetic intrinsic understanding of concepts of nature and life itself. Also there has been significant research done to establish the link between exposure to nature and positive effects on creativity. Environmental psychology deals with the restorative effects of nature on human creative experience. Kaplan in 1989 proposed that restoration from fatigue and stress is achieved by "soft fascination" provided by exposure to nature. This soft fascination reduces stress and enhances creativity or problem solving abilities by augmenting the ability to focus (Kaplan and Kaplan, 1989). Ulrich further established that nature reduces both psychological and physical stress in individuals with increasing abilities to perform cognitive tasks (Ulrich, 1983).

Different scholars have established design thinking as distinct from merely problem solving. Design thinking makes use of the brain's capacity to synthesize and holistically grasp the answer to a problem. Design thinking process is not a linear and sequential process, but as identified by Lawson, is a cyclic and iterative process (Lawson, 1990). Cross and Nathenson (1981) identify four opposing thinking modes namely; convergent vs divergent, reflective vs impulsive, field dependent vs independent and socialistic vs holistic. Designers mostly employ divergent, impulsive, independent and holistic modes of thinking. Design thinking incorporates developing multiple iterations of designs to tentatively and explanatively address the design problems. Designers approach problems by challenging the basic assumptions and provoking the basic premises. Their approach is freer and encourages new ways of looking at problems. They particularly make use of visual thinking that essentially liberates them from the rules of grammar and language.

Most design students are conversant in convergent thinking, where all patterns are analyzed to form solutions that are right or wrong. They have difficulty adjusting to design thinking mode where there is no right or wrong design. As
Lawson observes (1993: 10), "the need to think about the whole problem, or at least a great number of issues at once, is another of the features that make designing so challenging". It is imperative that foundation year of architecture should focus on developing creative and visual thinking abilities. Lateral thinking can work quite effectively as a design thinking tool. Lateral thinking makes use of considering a problem from multiple perspectives to shun the preconceived pattern of thoughts. The techniques can be classified into three themes. The first theme is to do away with any hindering pattern that blocks one from looking at a problem from a new perspective. De Bono calls it "challenging assumptions". The second theme of techniques enables the designer to step away from the problem to gain a broader view owing to the distance. This enables the person to come up with alternative routes to designing, this is termed as "generating alternatives" (De Bono, 1970). The third theme deliberately questions the logical patterns that our mind creates for efficiency and reroute its working with "provocation" (De Bono, 1970).

Conclusively, it can be established that nature can be a source of inspiration and design, generating impulse for human beings. By tossing constraints and opportunities it teaches the art of observation, improvisation and design. Moreover, studying nature imparts certain design thinking skills. It has been established that studying nature enables us to hone our observational skills. Studying nature also augments the abilities of the brain to look beyond the obvious and discover new patterns and linkages. Impulsive and lateral thinking modes deliberately induce the same qualities in the designer's thinking skills.

For a foundation year studio, studying nature can work on many levels. The core values of lateral thinking, namely challenging assumptions and provocation, woven smoothly into the design challenge can help students think out of the box. Nature provides no fixed answers and compelled the students to think of alternative interpretations of natural phenomenon and convert them into a coherent source of inspiration for a given design challenge.

\section{Foundation Studio Intent}

Ephemeral qualities of nature were explored in the studio as students were exposed to a variety of techniques and methods and creative processes. Starting from observation of nature and by recording those observations in variety of mediums, students gained confidence to comprehend and represent nature and natural phenomena later in their design exercises; as their decision-making in realistic representation of nature improved, so did the ability to extend imagination and innovation. 
The students at B.Arch. program of COMSAT University were expected to learn to be patient in observing and absorbing their surroundings. Starting from seeing, they moved on to the next step of noticing and then representing nature in a realistic manner in a variety of mediums. Using observation of nature as a spring board for leaping into the unknown world of imagination, lead to the next stage where abstraction was introduced (Figure 1).

More often than not artists develop design gradually during the process. Preconceived ideas change several times. In order to bring an invigorating energy in design one has to be open to chance effects and fresh possibilities of spontaneity. In architecture, this flexibility in design thinking might not happen exactly in this way, but while being close to the central idea, one should be open for new ways of looking. It is learning by doing, thinking through making and making through thinking and seeing. Presence of a practicing visual artist and architect in the studio helped develop a constant habit of self-reflection. Empowering students in defining their own questions and directions was an important part of self-education. As a team of teachers with diverse professional back grounds, the role was to stimulate interest in the design process not only by preparing handouts which clearly defined

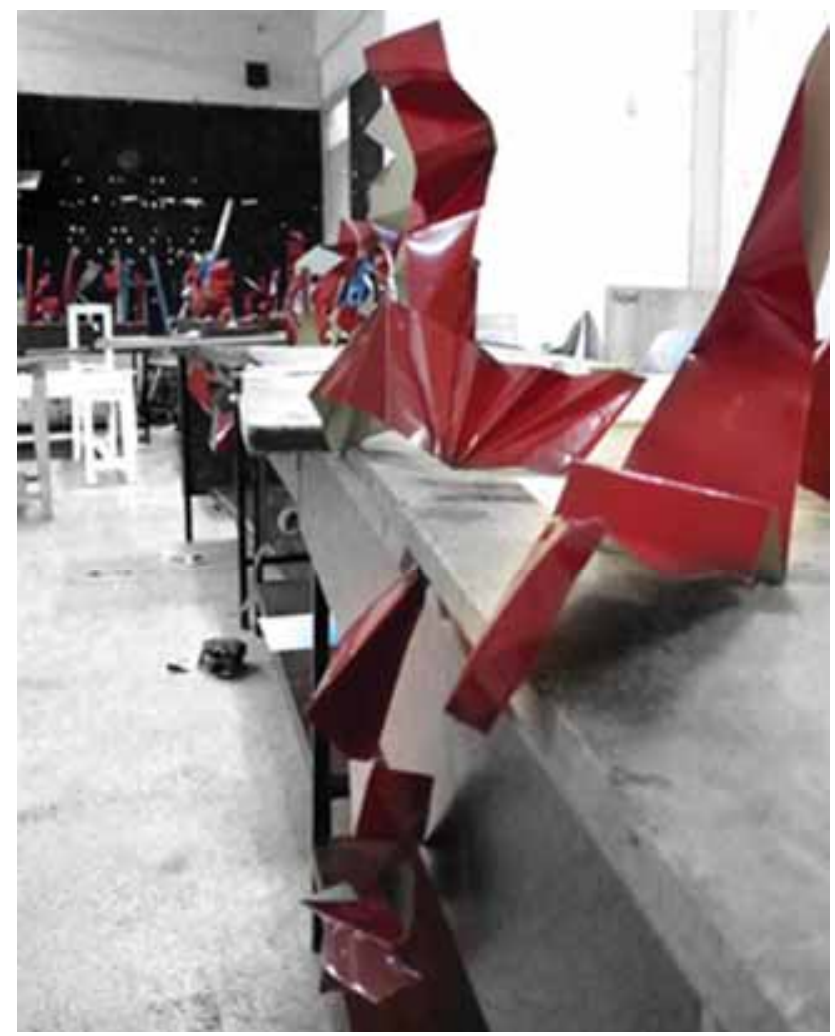

Figure 1: Study models of student experiments with wind objectives and directions, but also by encouraging design personalization process through lateral thinking.

\section{Studio Instruction Model and Design Outputs}

\section{General Assumptions and Studio Summary}

The abstract idea of lateral thinking, as elaborated by De Bono, (1970) is about restructuring previously derived and commonly established patterns and systems of thinking and designing, by consulting the core. The core in this case was assumed to be nature. Wind is the most usual natural phenomenon and abundant form of gas that one comes across in our day-to-day life. An obvious attribute of wind is abrupt and unexpected movement, which may cause the emergence of uneven and unforeseen pressure on surfaces, apart from sound and mixing of colors to generate other colors.

The teaching and learning model adapted for this studio exercise was 'lateral thinking', which was applied through designing studio instructions that lead students to explore and experiment design possibilities by imagining and interpreting the uneven blows of wind on surfaces.

\section{Instruction System}

Resource for idea generation in this exercise was identified wind in nature as the driving force. The studio task was titled as working with wind. Students were introduced to the very basic natural phenomenon and were asked to observe the qualities of wind. Students were then instructed to analyze their personal observations and were asked to reinterpret qualities of wind in another comparatively stable material (Figures 1 and 2).

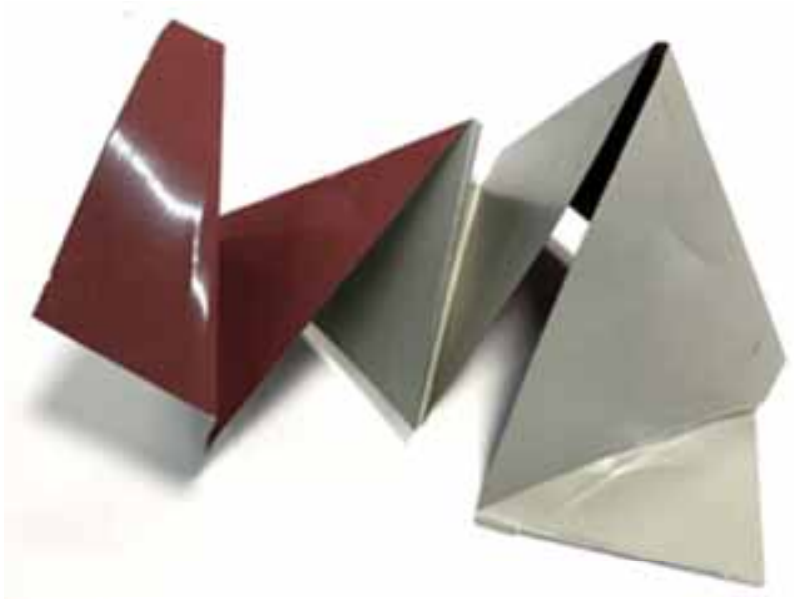

F igure 2: Study models of student experiments with wind 


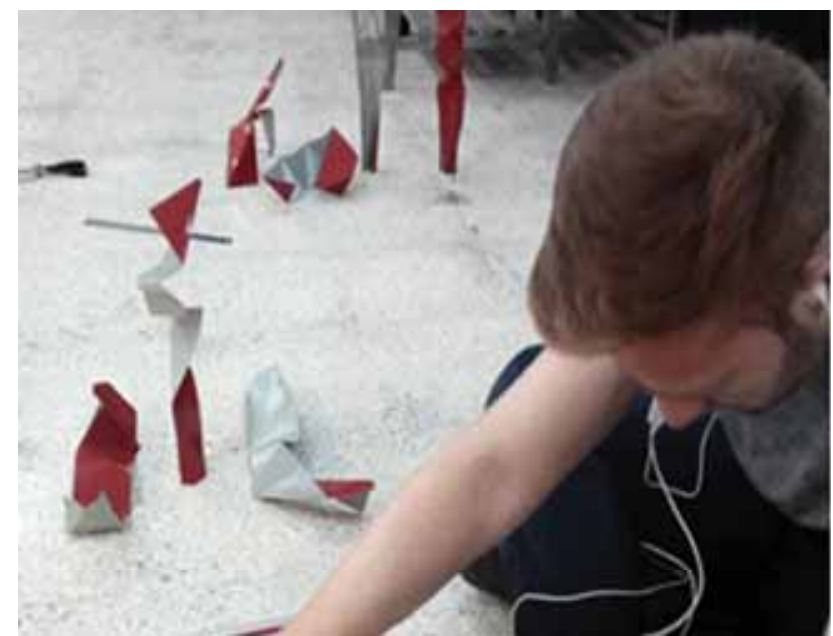

Figure 3: Student working with wind and focusing on balancing study models

Design discourses were initiated by indulging students in observing the phenomenon of wind movement. The students were given the task to observe the effect of wind on formal transformations of lightweight matter. After observing constant pushes and pulls of the invisible natural force they were asked to design structures that could withstand arbitrary blows of wind. Students experimented with a soft material i.e. colored tin sheet, to vividly express different potential formations as resultant occurrences of the physical natural phenomenon. An additional challenge of balancing steel strips for anticipated utility was also given (Figures 3 and 4).

\section{Stepwise Design Applications}

The students finally selected one object out of four iterations (Figure 4) and were instructed to modify the scale as well as the form to give it function of a working piece of furniture. On a scaled drawing of previously worked out forms, technical drawings (plan and elevations) were then drafted (Figure 5).

\section{Tin M odel Multiuse F urniture}

Using the previous model as an impression, a concept of furniture was introduced (Figure 6). The approach to the first project was multidimensional; based on the anthropological studies of a youth sitting on the ground cross-legged and studying, a rocking chair was designed, based on the thinking process behind hospital beds. All these points went together, and a simple tin sheet of 18 " to 5'-9" was bent five times to form a legless chair, using the weight of a person for stability, so that the back tin area could

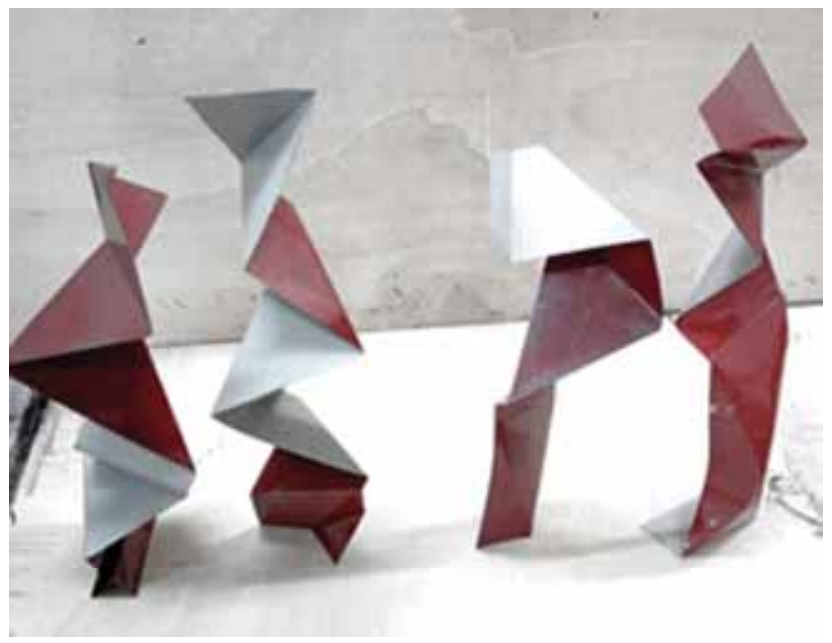

F igure 4: Resultant balanced models
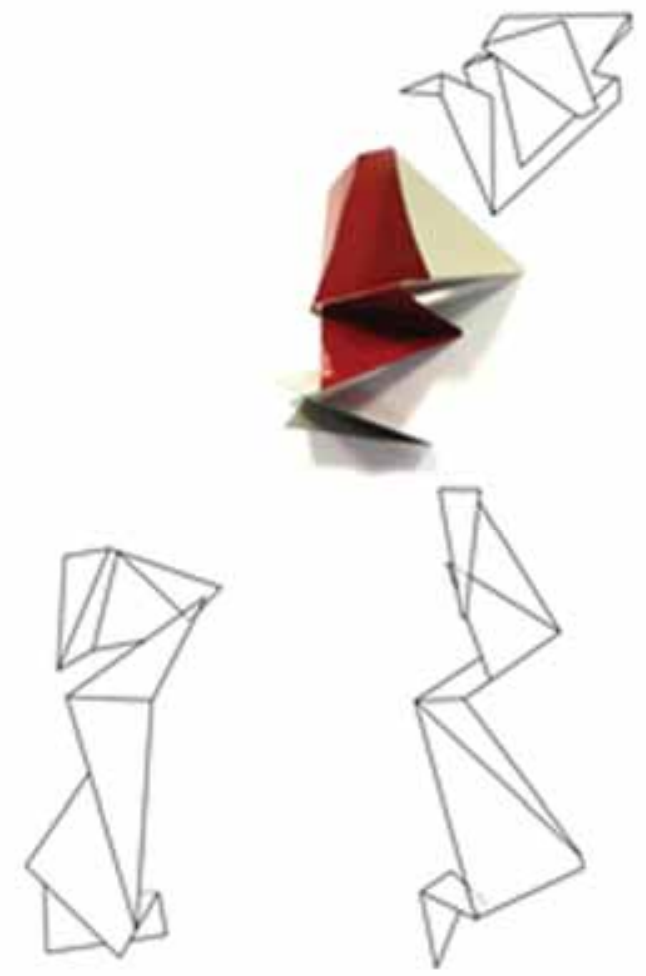

F igure: 5 Life size drafting of the selected model.

support the weight of the person. The front was used as a study table to hold a book or an electronic gadget. The person could rest by placing his or her legs on the study table, and the back could be rested on the back seat which functioned as a rocking chair (Figures 6 and 7). 


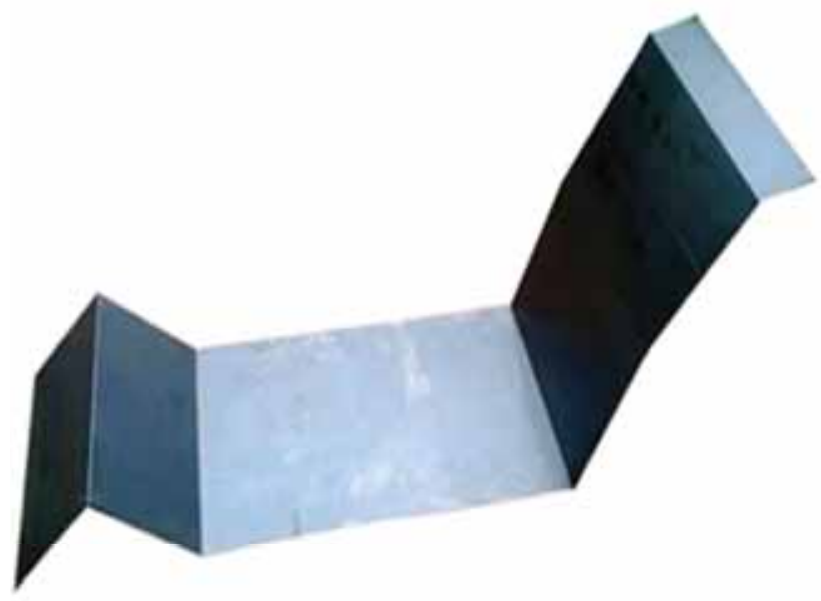

F igure 6: Furniture model on final display Medium: 18" X 5'-9", 16 gauge tin sheet

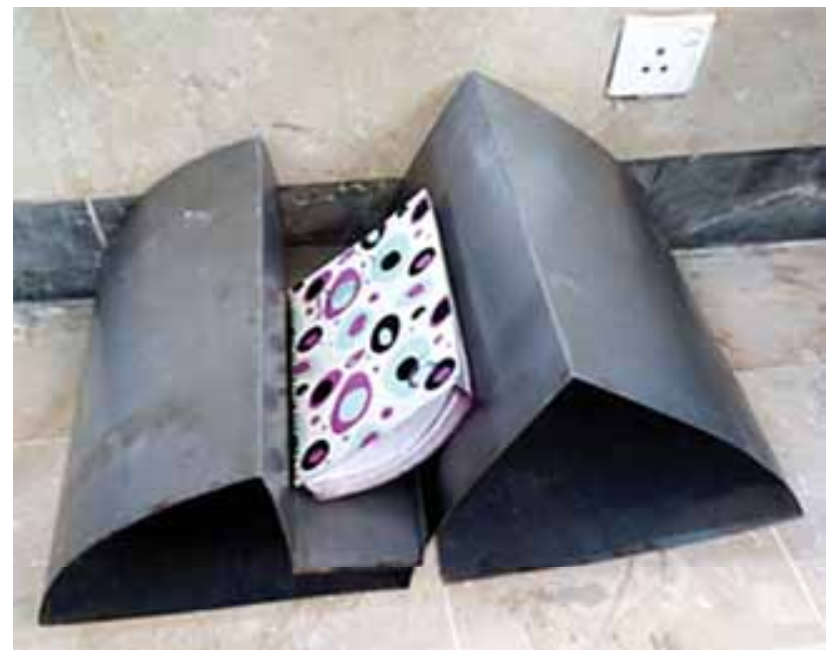

F igure 8: Magazine rack furniture model on final display

\section{Magazine Rack}

The second project was the design of a magazine rack. It was made out of another previously developed impulsive design. The exercise was instrumental to bring ideas and designs to life. According to the student this process helped understand the importance of observation and the idea of balance (Figure 8).

\section{Coffee Table}

In the third project the fabrication of furniture was done and a piece of furniture was designed using minimum cutting, support and relying on only folding techniques to support the furniture itself and the live load that was to be carried by the table (Figures 9 and 10).

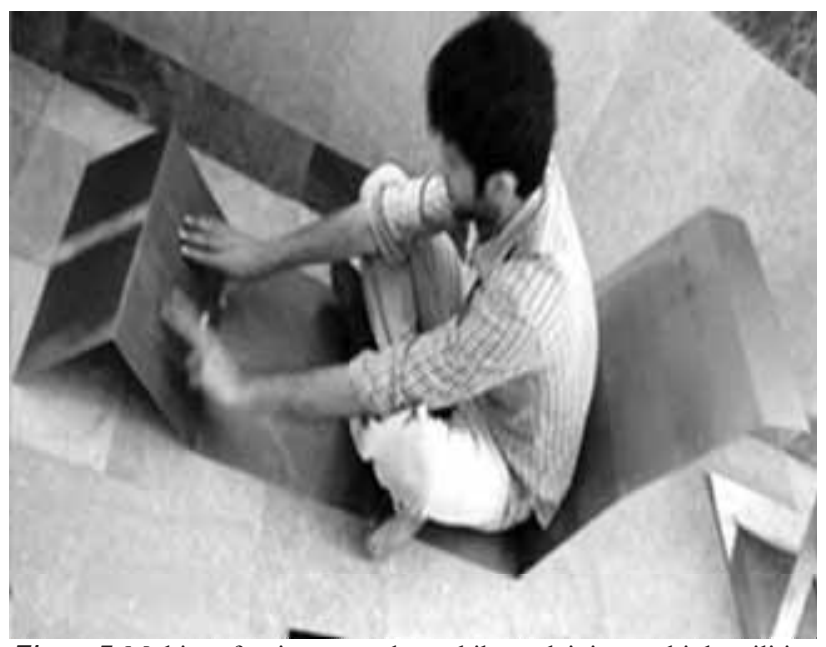

F igure 7: Multiuse furniture - student while explaining multiple utilities of the product

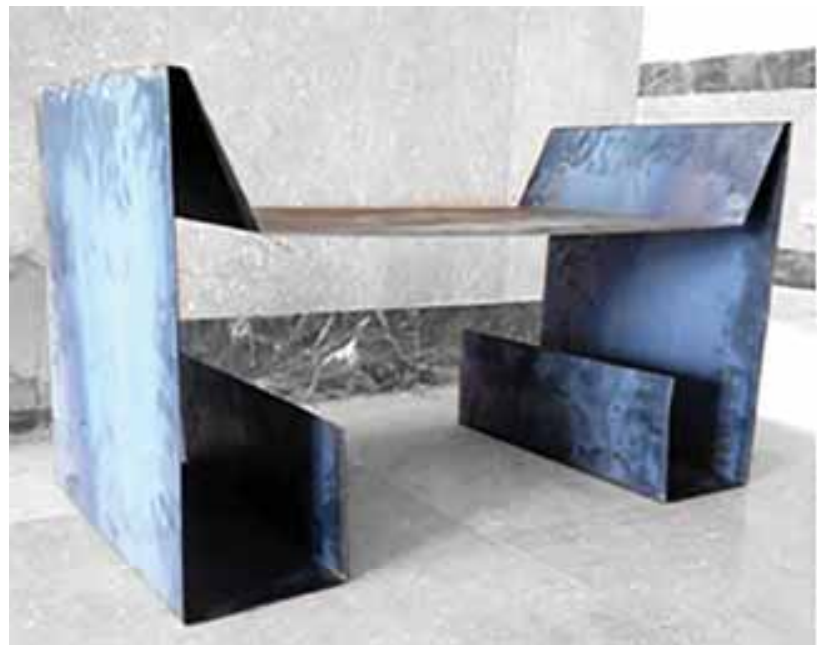

F igure 9: Furniture model on final display

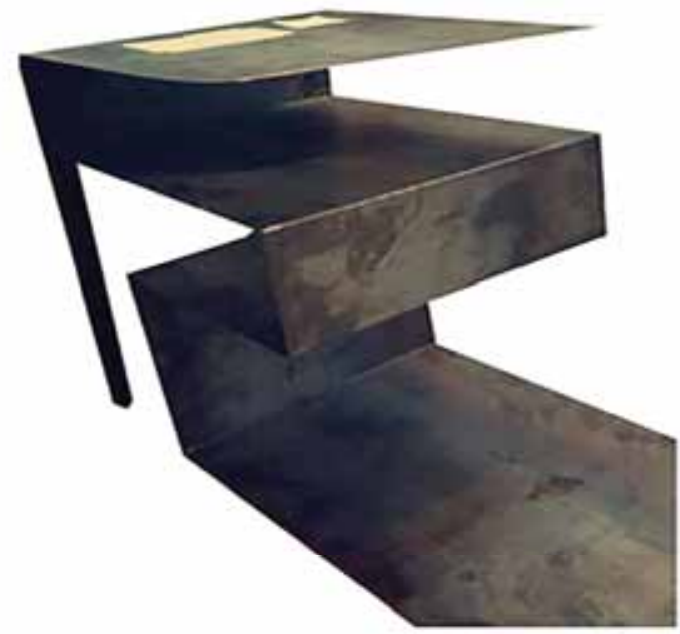

Figure 10: Furniture model on final display 


\section{Conclusions}

The meta objective of connecting the students to a conscious realization of experiencing, observing and rethinking the role of nature in their creative process was achieved. The design assignment was based on the idea of lateral thinking in foundation studio, bringing students closer to the goal of flexibility in architectural design thinking, so as to transform everyday experiences of surrounding into a meaningful design activity.

Furniture design project in the above case proved to be instrumental in changing prototypical perception of design. Students experimented with diverse materials; scaling up from concept models taught them the importance of studying intrinsic nature of materials, as some of the materials chosen for small scale models were not fit for larger versions. Looking at the same situation and idea from various perspectives taught them to re-examine their own work with fresh eyes.

Conclusively, foundation studio on a very basic level teaches multifaceted analysis process where different people perceive same things differently, and thus they can design more creatively. Students practically learn that unexpected solutions can emerge when a different pair of eyes observes the same phenomena of nature.

\section{REFERENCES}

Bailey, L.H., 1904, Leaf I: What is Nature-Study?, New York, Doubleday, Page and Company. Bayley, S., 2012, Ugly: The Aesthetics of Everything, Goodman Fiell, Hong Kong, Goodman Publisher. Cross, N., and, Nathenson, M., 1981, "Design Methods and Learning Methods". In: R.Jacques and JA. Powell ed. D esign Science. (s.l.); Surrey R. West bury House, IPC Business Press Ltd.

De Bono, E., 1970, Lateral Thinking: A Textbook of Creativity, New York Penguin Books.

Fletcher, Alan, 2001, The Art of Looking Sideways, Washington, Phaidon Press Ltd.

Global Status Report, 2017, "Towards Zero-Emission, Efficient, and Resilient Buildings and Construction Sector Paris", UN Environment and International Energy Agency.

Kellert, S. 1997, Kinship to Mastery: Biophilia in Human Evolution and Development, Washington, Island Press.

Kaplan, R. and Kaplan, S., 1989, The Experience of Nature: A P sychological Perspective, Cambridge, Cambridge University Press.

Lawson, Bryan. R., 1990, H ow Designers Think? The D esign Process Demystified, London, Butterworth Architecture.

Stern, 2006, "Stern Review: The Economics of Climate Change", viewed 20th January 2017, from http://www.wwf.se/source.php/1169158/Stern\%20Summary_of_Conclusion.pdf.

Ulrich S. Roger, 1983, “Aesthetic and Affective Response to Natural Environment”, Altman and Wholwill (eds.), H uman Behaviour and Environment, Vol-6, New York, Plenum: 85-125.

Raouf, S., Fuentes, M., Thomas, S., 2007, E cohouse: A D esign Guide, Third Edition, London Architectural Press, Routledge. Wines, James, 2008, Green Architecture, USA, Taschen. 